\title{
Implementasi Sistem Pakar Diagnosa Penyakit Jantung Pada Manusia
}

\author{
Cindy Pamela Cornelia Munaiseche ${ }^{1}$ \\ Teknik Informatika, Fakultas Teknik, Universitas Negeri Manado \\ e-mail: cindymunaiseche ${ }^{1} @$ unima.ac.id \\ Vivi Peggie Rantung ${ }^{2}$ \\ Teknik Informatika, Fakultas Teknik, Universitas Negeri Manado \\ Hiskia Kamang Manggopa ${ }^{3}$ \\ Pendidikan Teknologi Informasi dan Komunikasi, Fakultas Teknik, Universitas Negeri Manado \\ dr. Nancy Silvia Bawiling ${ }^{4}$ \\ Ilmu Kesehatan Masyarakat, Fakultas Ilmu Keolahragaan, Universitas Negeri Manado
}

\begin{abstract}
ABSTRAK
Sistem pakar adalah sebuah sistem yang berusaha mengadopsi pengetahuan manusia ke dalam komputer, sehingga komputer dapat menyelesaikan masalah seperti yang dilakukan oleh seorang pakar/ahli. Tujuan dari penelitian ini untuk merancang sebuah aplikasi sistem pakar untuk mendiagnosa penyakit jantung dengan menggunakan metode forward chaining sebagai salah satu teknik infernsi yang bertujuan menemukan gejala penyakit yang ditampilkan dalam bentuk pertanyaan-pertanyaan. Organ jantung dipilih karena banyak tingkatkematian yang diakibatkan oleh serangan jantung mendadak. Peancangan aplikasi sistem pakar ini terdiri dari tujuh tahapan, yaitu: studi pendahuluan, pengumpulan data, analisis data, desain sistem, implementasi sistem, evaluasi sistem, dan terakhir penarikan kesimpulan. Aplikasi perangkat lunak sistem pakar yang dibangun ini dapat mengenal jenis penyakit jantung setelah berkonsultasi dengan menjawab beberapa pertanyaan yang ditampilkan oleh sistem.
\end{abstract}

Kata kunci: Sistem pakar, forward chaining, penyakit jantung, serangan jantung, teknik inferensi

ABSTRACT

Expert System is a system that is trying to adopt human knowledge into a computer, so that the computer can resolve the issue as was done by experts. The purpose of this study to design an application of expert system for diagnosis the heart diseases by using forward chaining method as one of inference technique that aims to discover symptoms of the disease that is displayed in the form of questions. The heart organ chosen because many mortality rates are caused by sudden heart attacks. The expert system application design consists of seven stages: preliminary studies, data collection, data analysis, system design, system implementation, system evaluation and the last, drawing conclusions. Expert system software application built to recognize the type of heart disease after consultation by answering a few questions displayed by the system, and can infer the type of heart diseases suffered by the patient. In addition, an application created to provide solutions or actions that can be performed by patients in relation to heart disease he suffered.

Keywords: Expert system, forward chaining, heart disease, heart attack, inference technique

\section{PENDAHULUAN}

Kecerdasan buatan atau Artificial Intelligence (AI) merupakan salah satu bagian ilmu komputer yang membuat agar mesin (komputer) dapat melakukan pekerjaan seperti dan sebaik yang dilakukan oleh manusia (Kusumadewi, 2003). Salah satu cabang dari Artificial Intelligence adalah Sistem Pakar (Expert System). Menurut Doran (1988), sistem pakar adalah: a computer program which uses non-numerical domain-specific knowledge to solve problems with a competence comparable with that of human expert. Definisi sistem pakar menurut Durkin adalah suatu program komputer yang dirancang untuk memodelkan kemampuan penyelesaian masalah yang dilakukan seorang pakar (Kumar, 2010). 
Sebuah sistem pakar harus memberikan suatu dialog dan setelah diberikan suatu jawaban, sistem pakar dapat memberikan nasehat atau solusi (Naser dan Zaiter, 2008). Seorang pakar dengan sistem pakar mempunyai banyak perbedaan. Tujuan pengembangan sistem pakar sebenarnya tidak untuk menggantikan peran para pakar, namun untuk meng-implementasikan pengetahuan para pakar ke dalam bentuk perangkat lunak, sehingga dapat digunakan oleh banyak orang dan tanpa biaya yang besar (Sulistyowati dan Hidayat, 2008). Ada berbagai macam sistem pakar dalam bidang kedokteran, diantaranya sistem pakar untuk mendiagnosa penyakit mata, kulit, mulut, organ dalam, dan lain-lain.

Untuk penelitian ini, jenis penyakit yang didiagnosis oleh sistem pakar adalah jenis penyakit jantung. Dipilihnya organ jantung karena jantung berperan penting dalam memompa darah ke seluruh tubuh. Banyak orang yang meninggal dikarenakan serangan jantung mendadak. Peran dokter spesialis sangat diperlukan sekali, tetapi peran dokter tersebut terbentur keterbatasan dalam melakukan konsultasi penyakit antara dokter dengan pasien, karena jumlah pasien yang begitu banyak hanya ditangani oleh satu atau dua dokter spesialis saja. Dan pada umumnya penderita penyakit jantung sering mengabaikan serta kurang memahami penyebab dan gejala terjadinya penyakit jantung. Hal inilah yang menjadi kendala dalam komunikasi antara pasien dengan dokter mengenai penyakit jantung yang dideritanya.

Hambatan-hambatan menyebabkan sulitnya melakukan konsultasi penyakit jantung dapat diatasi dengan adanya kemajuan teknologi, yaitu melalui pembuatan atau pengembangan aplikasi sistem pakar untuk mendiagnosa penyakit jantung pada manusia. Hal ini sesuai dengan salah satu program dan jenis kegiatan sekaligus menjadi topik riset yang diunggulkan oleh Universitas Negeri Manado di bidang pusat penelitian (puslit) Teknologi Informasi dan Komunikasi (TIK), yaitu pemanfaatan TIK melalui pengembangan perangkat lunak (software) aplikasi cerdas, dalam hal ini yaitu sistem pakar (sesuai renstra penelitian Unima).

Tujuan dari penelitian ini, yaitu: mensubstitusikan pengetahuan manusia ke dalam suatu bentuk perangkat lunak aplikasi sistem pakar untuk mendiagnosa penyakit jantung dengan menggunakan metode inferensi forward chaining dan mengembangkan suatu sistem pakar yang dapat digunakan dengan mudah oleh pengguna (user friendly) dalam memberikan solusi dan akses informasi berupa tindakan pencegahan atau cara penanganan terhadap suatu jenis penyakit jantung.

Penggunaan metode forward chaining sebagai salah satu inferensi dalam sistem pakar ini, dikarenakan data dan fakta dalam melakukan proses penelitian telah didapatkan dan dari data atau fakta tersebut dapat dibuat sistem yang akan memberikan sebuah konklusi atau solusi berdasarkan atas sekumpulan data dan fakta tersebut. Dengan menggunakan teknik inferensi ini pula peluang dalam mendapatkan suatu konklusi yang lebih spesifik dapat dengan mudah diperoleh (Kusumadewi, 2009).

Perangkat lunak sistem pakar yang akan dibuat dapat mengenali jenis penyakit jantung setelah melakukan konsultasi dengan menjawab beberapa pertanyaan-pertanyaan yang ditampilkan oleh aplikasi sistem pakar serta dapat menyimpulkan beberapa jenis penyakit jantung yang di derita oleh pasien dan memberikan solusi berupa tindakan pencegahan atau cara penanganan yang 
dapat dilakukan sehubungan dengan penyakit jantung yang dideritanya.

Melalui penelitian ini diharapkan dapat memberikan manfaat dalam membantu proses sosialisasi jenis penyakit jantung pada manusia beserta gejala-gejalanya dan solusinya bagi masyarakat, dapat memberikan sumbangan kepada tenaga medis untuk menjadi bahan referensi dan menjadi penuntun bagi masyarakat (pasien) untuk melakukan tindakan awal yang harus diambil jika mengetahui seberapa besar kemungkinan menderita penyakit jantung (pendeteksian dini).

\section{METODE}

Bahan yang digunakan dalam penelitian ini, yaitu data-data dari objek penelitian berupa: nama-nama jenis penyakit jantung pada manusia berserta gejala-gejalanya, keterangan penyakit dan solusi pengobatan/pencegahannya; serta literatur-literatur atau buku acuan yang berhubungan dengan pembuatan program aplikasi sistem pakar dan penyusunan laporan penelitian.

Peralatan penunjang penelitian yang diperlukan terdiri atas:

1) Perangkat keras, yaitu seperangkat komputer yang memiliki spesifikasi secukupnya untuk keperluan merancang sistem atau menjalankan perangkat untuk PHP dan MySQL yang berjalan diatas sistem operasi Windows atau Linux.

2) Perangkat lunak, yaitu: Windows 7 , Apache (web server), MySQL (database server), PHP (programming language). Menggunakan paket XAMPP (Apache, MySQL dan PHP). Penelitian ini dilakukan dengan tahapan-tahapan sebagai berikut:

Studi Pendahuluan: Pada tahap ini penulis mengumpulkan infomasi dan mempelajari materi serta sumber-sumber data yang berhubungan dengan sistem pakar, metode forward chaining, dan pendekatan/penalaran berbasis aturan (rule-based reasoning).

Pengumpulan Data : Sumber data yang digunakan dalam sistem pakar untuk mendiagnosis penyakit jantung pada manusia meliputi data jenis penyakit jantung, data gejala yang menyertai penyakit jantung tersebut, keterangan penyakit dan solusi yang diberikan. Data yang diperlukan dalam penelitian ini diperoleh dari: 1) Studi pustaka, yaitu dengan mengumpulkan data atau informasi dengan cara melakukan studi pada beberapa literatur dan sumber catatan lain (artikel); 2) Konsultasi melalui wawancara dengan pakar (dokter spesialis jantung).

Analisis Data : Data-data yang telah diperoleh kemudian dirangkum untuk dianalisa dengan cara: 1) Membuat daftar jenis-jenis penyakit jantung beserta kode penyakit; 2) Membuat tabel pengetahuan atau tabel relasi/hubungan antara penyakit jantung dan gejalanya; 3) Membuat RuleBased System (aturan-aturan atau kaidah) atau yang disebut representasi pengetahuan yang berkaitan dengan penyakit jantung tersebut.

Desain Sistem : Perancangan sistem ini meliputi: desain proses, diagram konteks, diagram arus data atau data flow diagram (DFD), perancangan basisdata, dan rancangan antarmuka pemakai dan sistem (user interface).

Implementasi Sistem : Aktivitas yang dilakukan pada tahap ini, yaitu pemrograman atau koding. Tahap ini adalah penerjemahan rancangan dalam tahap desain ke dalam bahasa pemrograman komputer yang telah ditentukan sebelumnya. Dalam penelitian ini menggunakan bahasa pemrograman PHP yang digunakan untuk mengatur 
komputer agar bekerja sesuai dengan maksud masing-masing instruksi.

Pengujian Sistem : Setelah sistem selesai dibuat maka dilakukan pengujian dengan memberikan serangkaian pertanyaan yang akan dijawab oleh pasien, kemudian sistem akan memberikan diagnosa jenis penyakit dan gejala yang diderita pasien.

Penarikan Kesimpulan : Pada tahap ini dilakukan penarikan kesimpulan terhadap hasil yang sudah dicapai.

\section{HASIL DAN PEMBAHASAN}

Memuat hasil dan pembahasan tentang penelitian yang dilakukan. Hasil yang akan dibahas di sini menyangkut analisis data, desain sistem, implementasi sistem dan evaluasi sistem.

\section{Analisis Data}

Daftar dan kode penyakit mata beserta gejala: Perangkat lunak sistem pakar ini dapat mendiagnosa 10 jenis penyakit jantung dengan 33 gejala penyakit.

Rule-Based System: Untuk mengenali jenis penyakit mata pada manusia perlu adanya rule-rule atau aturan dalam penelusuran sistem pakar. Terdapat 10 Aturan yang dibutuhkan sesuai dengan tabel dan hirarki forward chaining yang disebut dengan Rule-Based System.

\section{Desain Sistem}

Desain Perangkat lunak sistem pakar ini terdiri dari: 1) Basis Data : Perangkat lunak sistem pakar ini menggunakan basisdata (database) yang diberi nama pakarjantung_db yang memiliki sembilan tabel terdiri dari lima tabel utama dan empat tabel bantu yang saling terkait;

2) Diagram Konteks (Context Diagram) dan Data Flow Diagram (DFD): Diagram konteks bertujuan untuk melihat informasi sistem pakar diagnosa penyakit jantung pada proses sistem secara keseluruhan, dapat dilihat pada Gambar 1. Data Flow Diagram (DFD) atau Diagram Arus Data menggambarkan bagaimana data mengalir melalui suatu proses yang saling berkaitan.

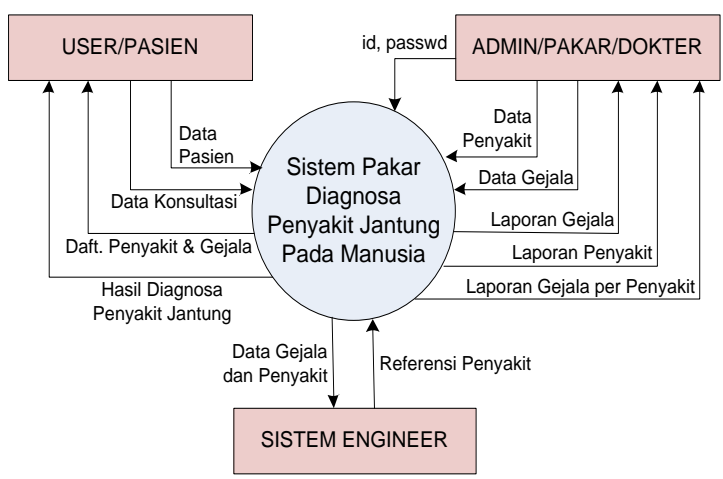

Gambar 1. Diagram Konteks

\section{Implementasi Sistem}

Antarmuka Pengguna (User Interface) merupakan antarmuka yang digunakan oleh user atau pengguna umum. Pada menu utama aplikasi terdiri dari lima menu, yaitu: menu Home, Daftar Penyakit, Konsultasi, Login Pakar, dan Kontak. (Gambar 2).

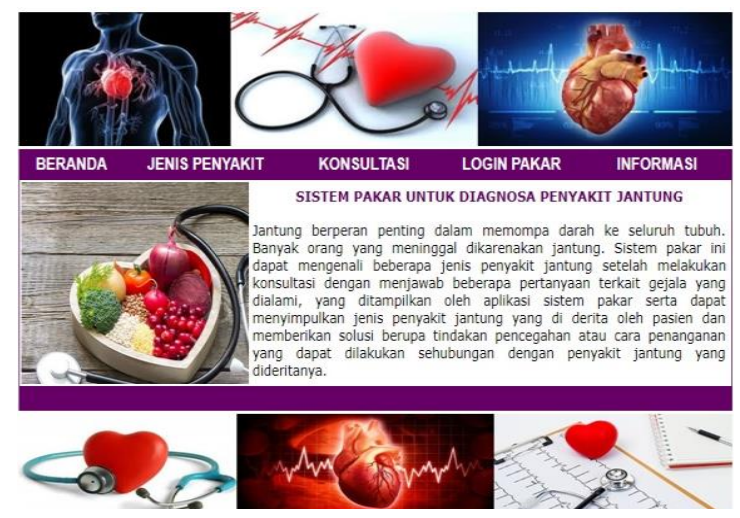

Gambar 2. Antarmuka menu utama

Form Konsultan dan Hasil Diagnosa merupakan tampilan jendela aplikasi untuk melakukan proses konsultasi pakar. Pasien (user) dapat langsung menjawab option Benar (YA) atau Salah (TIDAK) dari 
pertanyaan-pertanyaan yang ditampilkan pada kolom tersebut (Gambar 3).

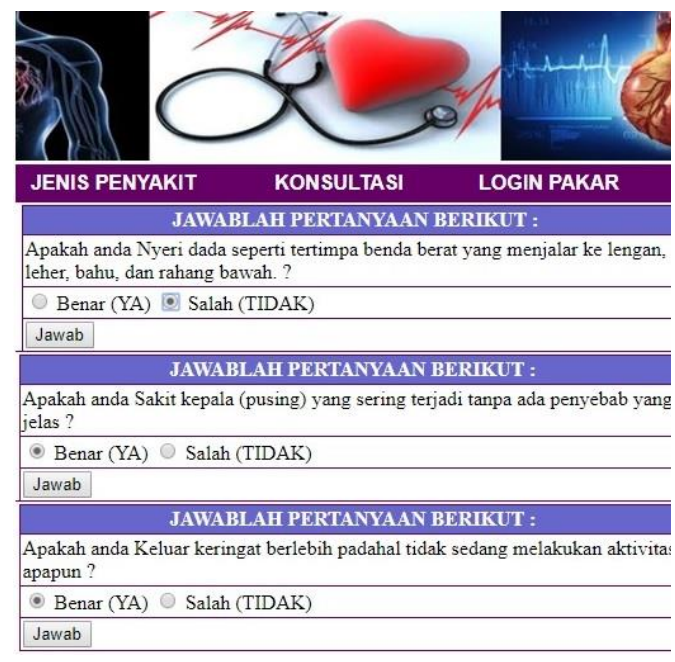

Gambar 3. Form Konsultasi

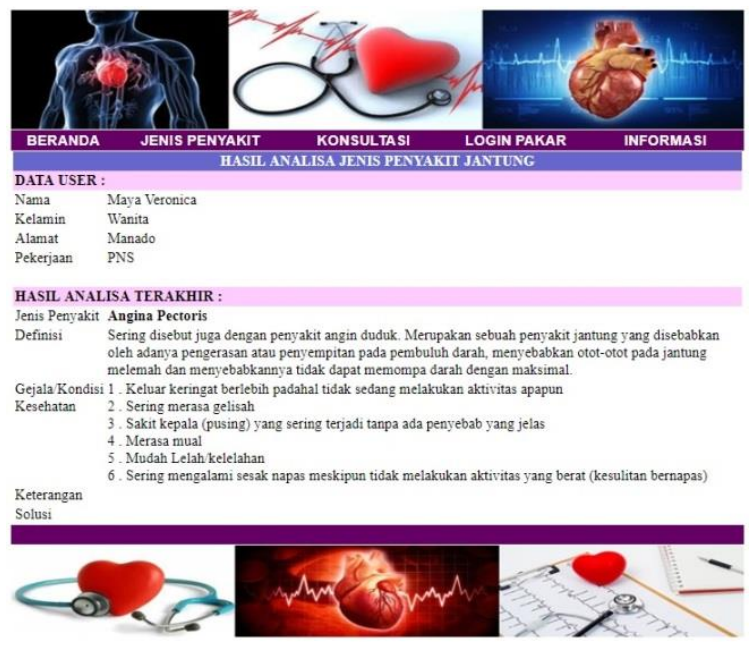

Gambar 4. Hasil diagnosa

Selanjutnya sistem akan dapat menyimpulkan jenis penyakit yang di derita oleh pasien pada Hasil analisa penyakit jantung yang menampilkan data pasien dan hasil analisa akhir berupa nama penyakit, gejala, dan definisi penyakit (Gambar 4).

\section{Evaluasi Sistem}

Untuk mendapatkan data yang akurat, maka dapat dilakukan beberapa uji coba sistem atas jalannya sistem pakar tersebut.
Dari serangkaian pertanyaan yang dijawab oleh pasien/user (Gambar 3), hasil diagnosa pada Gambar 4 menunjukkan bahwa pasien tersebut mengalami jenis penyakit jantung Angina Pectoris dengan gejala: keluar keringat dingin padahal tidak sedang melakukan aktivitas apapun, sering merasa gelisah, sakit kepala (pusing) yang sering terjadi tanpa adanya penyebab yang jelas, merasa mual,mudah lelah, sering mengalami sesak napas padahal tidak melakukan aktivitas yang berat (kesulitan bernapas).

\section{PENUTUP \\ Kesimpulan}

Dari penelitian ini dapat ditarik beberapa kesimpulan, yaitu:

1. Pembuatan aplikasi sistem pakar untuk mendiagnosa penyakit mata pada manusia dapat menggunakan proses penelusuran dengan metode forward chaining sebagai teknik inferensi dan pendekatan berbasis aturan (rule-based reasoning).

2. Pasien dapat langsung berkonsultasi dengan mudah melalui perangkat lunak sistem tanpa harus berkonsultasi dengan seorang pakarnya (dokter spesialis jantung) terlebih dahulu.

\section{Saran}

Dari hasil penelitian yang sudah diperoleh disarankan sebaiknya menambahkan jenis penyakit jantung yang lain dan untuk penelitian ke depannya dapat menggunakan teknik inferensi yang lain, misalnya: backward chaining atau gabungan antara forward chaining dan backward cahining. 


\section{UCAPAN TERIMA KASIH}

Mengucapkan terima kasih kepada Kemenristek Dikti yang sudah mendanai riset ini melalui DRPM untuk skema Penelitian Terapan Unggulan Perguruan Tinggi (PTUPT)

\section{DAFTAR PUSTAKA}

Doran, J. 1988. Expert System and Archaeology; What lies ahead? In Ruggles and Rahtz (eds) Computer and Quantitative Methods in Archaeology. BAR International series 446.

Kumar, S., Prava, D. 2010. An Expert System for Diagnosis of Human Diseases. International Journal of Computer Applications. Volume 1. Nomor 13.

Kusumadewi, S., Fauzijah, A., Khoiruddin A. A, et.al. 2009. Informatika Kesehatan. Graha Ilmu dan Rumah Produksi Informatika, Yogyakarta.

Kusumadewi, S. 2003. Artificial Intelligence (Teknik dan Aplikasinya). Edisi Pertama. Graha Ilmu, Yogyakarta.

Naser, A., Zaiter, A. 2008. An Expert System For Diagnosing Eye Disease Using Clips. Journal of Theoretical and Applied Information Technology.

Sulistyohati, A., Hidayat, T. 2008. Aplikasi Sistem Pakar Diagnosa Penyakit Ginjal Dengan Metode Dempster-Shafer. Proceeding of SNASTI.

\section{RIWAYAT HIDUP PENULIS}

Cindy Pamela Cornelia Munaiseche.

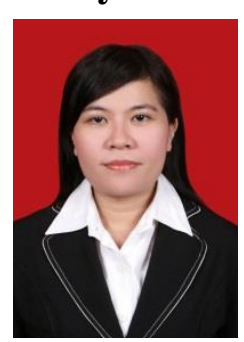

Lahir di Manado, 27 November 1978. Staf pengajar di Program Studi Teknik Informatika, Fakultas Teknik Universitas Negeri Manado, Studi S1 Bidang Teknik Elektro, Universitas Sam Ratulangi, Manado, lulus tahun (2003); S2 Sistem Komputer dan Informatika (SKI), Universitas Gadjah Mada, Yogyakarta, lulus tahun 2011. 